RESEARCH ARTICLE

\title{
Typing of Methicillin-Resistant Staphylococcus aureus Isolate from Healthcare Workers in Larestan, Iran
}

\author{
Mehdi Ebadi ${ }^{1}$, Hossein Ashrafi ${ }^{2}$ \\ ${ }^{1}$ Department of Microbiology, Islamic Azad University, Larestan Branch, Larestan, Iran \\ ${ }^{2}$ Department of Laboratory, Larestan University of Medical Science, Larestan, Iran
}

\begin{abstract}
Objective: The aim of this study was to determine the antimicrobial susceptibility and cassette chromosome typing in Methicillin-Resistant Staphylococcus aureus (MRSA) isolated from healthcare workers.

Methods: Two hundred thirty nasal swabs were collected from healthcare workers of three hospitals in Larestan, Iran. Antibiotic susceptibility was determined by disk diffusion method according to CLSI guideline. The minimum Inhibitory concentration (MIC) of vancomycin and screening test with methicillin were measured by E-test and agar screen plate procedures. Cefoxitin disc diffusion test was performed. MRSA isolates were selected and investigated for mecA gene and SCCmec typing by multiplex-PCR, then five methods were compared.

Results: In total, $37 \mathrm{~S}$. aureus were isolated, 28 were defined as MRSA. Frequency of SCCmec types were as nine SCCmec I, eight SCCmec IV, five SCCmec II, four SCCmec V and two SCCmec III. In this study, 75\% of isolates were $C A-M R S A, 25 \%$ were $H A-M R S A$. Evaluation of antibiotic resistance showed the greatest resistance to penicillin and the lowest resistance was observed to vancomycin and by E-test method $28.5 \%$ of isolates were intermediate resistance to vancomycin. However, screening test detected $92.8 \%$ resistance with oxacillin and 28 of isolates were resistant with Cefoxitin disc diffusion. For these 28 isolates mecA was positive.

Conclusion: As a result, in our S. aureus isolates methicillin resistance was $75.7 \%$. The most frequent type was $S C C m e c$ I. Our result showed high rates of antibiotic resistance specially to methicillin in the $S$. aureus isolated hospitals that is a serious warning to the treatment of infection caused by this bacterium. J Microbiol Infect Dis 2018; $8(1): 1-7$
\end{abstract}

Keywords: Methicillin-resistant Staphylococcus aureus, SCCmec, mecA

\section{INTRODUCTION}

The resistance of bacteria to antimicrobial agents is a global challenge in the $21^{\text {st }}$ century. $S$. aureus is a leading cause for wide range of mild skin infection to endocarditis or necrotizing pneumonia in the hospital and communities [1]. Methicillin, the first synthetic penicillin was used in 1961 for the treatment of $S$. aureus infections and methicillin resistant strains appeared from hospitals in this year. Resistance to methicillin is due to the presence of the staphylococcal cassette chromosome mec (SCCmec) element, which is a class of mobile genetic element that carries the methicillin resistant determinant $\operatorname{mec} A$ [2].
MRSA produces an additional penicillin binding protein (PBP2a), which has low binding affinities for most of the penicillin as well as cephem antibiotics [3]

MRSA was generally considered to be hospital associated (HA-MRSA) but strains of MRSA acquired from community (CA-MRSA). CAMRSA strains possess small mobile SCCmec type $I V$ or $V$ genetic elements which contain mecA gene with antibiotic resistance gene, while HA-MRSA strains than larger SCC mec (Type I, II, III) elements and have Multi Drug Resistant (MDR) gene [4]. CA-MRSA strains separated in patients who have prolonged bed rest in a hospital but HA-MRSA seen in patients who were for more than 48 hours [5].

Correspondence: Dr. Mehdi Ebadi, Department of Microbiology, Islamic Azad University, Larestan Branch, Larestan, Iran 
The strains of CA-MRSA in comparison with $H A$ MRSA possess a high attack rate in outbreak settings, were more capable to produce Penton Valentin Leukocidin (PVL) toxin. This bipartite toxin is an active pore-forming toxin against human polymorphonuclear cells, monocytes and macrophages. In some studies, the pneumonia related to PVL production with CA-MRSA strains have been reported with the $37 \%$ mortality rate in 48 hours and in some other studies this rate increased to $75 \%[6,7]$.

The SCCmec typing in the method of Multiplex PCR was used not only in differentiation of community and hospital strains, but also as a useful method in monitoring over multi-drug resistant HA-MRSA strains and virulent $C A$ MRSA strains [8]. From a therapeutic point of view, vancomycin is the last used drug that is used extensively in the hospital environment.

Today, the biggest challenge and concern in hospitals is the creation of an infection with MDR MRSA strains that lack effective alternative drug, therefore vancomycin was used for treatment of MRSA. However, because of emergence vancomycin intermediate and resistant strains of S.aureus resulted in treatment failure [9]. In the past two decades, the prevalence of MRSA strains has increased in many parts of the world. For example, in a study in Iran among 235 isolates of $S$. aureus, 112 strains (47.5\%) were MRSA [10].

Due to the fact that in Larestan, there was no accurate report on the frequency of infection with MRSA in the hospitals of the region. Therefore, the purpose of present study was to detect methicillin resistance gene and evaluate the cassette chromosomal genotype and determine the antibiotic susceptibility pattern in MRSA strains isolated from healthcare worker in Larestan, Iran.

\section{METHODS}

\section{Sample collection and identification of bacteria}

This descriptive cross sectional study was conducted between February and March 2015 in Emam Reza Hospital bacteriology laboratory in the City of Larestan, South-west Iran. Samples were taken from one $\mathrm{cm}$ inside the nostrils with swab. The samples were transferred to the laboratory and inoculated in Brain Hearth infusion broth (Merck, Germany) then inoculated into Manitol salt agar (Merck, Germany) and incubated at $37{ }^{\circ} \mathrm{C}$ for $18-24$ hours. The colonies that grew with a golden-yellow color were considered as $S$. aureus colonies. The identification as an $S$. aureus colony was confirmed by catalase, coagulase, DNase production [11]. The individual colonies were preserved in skim milk (Merck, Germany) and $20 \%$ glycerol at $-20{ }^{\circ} \mathrm{C}$ for further analyses

Demographic information about healthcare workers sex, age, hospital units (ICU, surgical, Emergency, Radiology, children) history of taking the last antibiotic, a history of infection between people with MRSA were obtained from hospital medical records and questionnaire forms.

\section{Antibacterial susceptibility testing}

The antibacterial susceptibility pattern of MRSA isolates to 6 antibiotics including Cotrimoxazole (SXT) $(25 \mu \mathrm{g})$, Vancomycin $(30 \mu \mathrm{g})$, Erytromycin $(15 \mu \mathrm{g})$, Penicillin $(10 \mu \mathrm{g})$, Chloramphenicole (30 $\mu g)$, Clindamycin $(2 \mu \mathrm{g})$ (Mast Diagnostic UK) was tested by the Kirby-Bauer agar disk diffusion breakpoint method based on the Clinical Laboratory standard Institute (CLSI, 2012) guidelines. The CFU/ml of inoculums was adjusted to $1 \times 10^{8}, 100 \mu \mathrm{l}$ were spread all over Muller-Hinton agar. Muller-Hinton cultural was used in the temperature of $35{ }^{\circ} \mathrm{C}$ and for a period 18 hours [12].

\section{MRSA Screening}

MRSA screening test was performed with agar screen method. An agar screen plate was supplemented with $2.5 \% \mathrm{NaCl}$ and $6 \mu \mathrm{g} / \mathrm{ml}$ Oxacillin (Sigma, USA) for gross isolation of methicillin-resistant isolates. This test was carried out according to the CLSI guidelines (CLSI, 2012). A McFarland 0.5 suspension was spotted onto Muller Hinton agar containing 2.5\% $\mathrm{NaCl}$ and $6 \mu \mathrm{g} / \mathrm{ml}$ Oxacillin and incubated at 35 ${ }^{0} \mathrm{C}$ for $24 \mathrm{~h}$ [13].

If any growth was detected, the isolates were considered MRSA. All the isolates were subjected to cefoxitin (Sigma, USA) disk diffusion test using a $30 \mu \mathrm{g}$ disc. A $0.5 \mathrm{Mc}$ Farland standard suspension of the isolate was made and culture done on Muller-Hinton agar. Plates were incubated at $37{ }^{\circ} \mathrm{C}$ for $18 \mathrm{~h}$ and an inhibition zone diameter $\leq 19 \mathrm{~mm}$ was reported 
as Oxacillin resistant and $\geq 20 \mathrm{~mm}$ was considered as Oxacillin sensitive.

MIC vancomycin for each isolates was measured by $\mathrm{E}$ strip test (E-test) (Bio Disk Biomerieux, France) according CLSI guidelines. The MIC $<4 \mu \mathrm{g} / \mathrm{ml}$ was considered susceptible, MIC 4-8 $\mu \mathrm{g} / \mathrm{ml}$ considered Intermediate and MIC $32 \mu \mathrm{g} / \mathrm{ml}$ considered resistant to vancomycin.

The standard strains of $S$. aureus ATCC 25923 were used for negative control (Methicillin resistance), and S. aureus ATCC 33591 as positive control (Methicillin resistance) [14].

DNA extraction and amplification of SCC mec complex CTAB method was used to extract DNA [15]. The multiplex polymerase chain reaction (PCR) assay for SCC mec type used nine pairs of primers (Qiagen kit), including those for subtype I, II, III, IVa, IVb, IVc, IVd, V, as well as primers for the mecA gene [16] (Table 1).

The reaction mixture included $25 \mu \mathrm{L}$ master mix (containing Taq polymerase, $\mathrm{MgCl} 2$ and dNTP), $5 \mu \mathrm{L}$ tempelate DNA, $8 \mu \mathrm{L}$ distilled water, $1 \mu \mathrm{L}$ Forward primer, $1 \mu \mathrm{L}$ Reverse primer (Sigma Aldrich). PCR program was performed at the Thermal Cycler system (Eppendorf Germany), for $\operatorname{mec} A$ gene detection and it was consisted of an initial denaturation at $94{ }^{\circ} \mathrm{C}$ for $5 \mathrm{~min}$ and then 30 cycles consisting of denaturation at 94 ${ }^{0} \mathrm{C}$ for $1 \mathrm{~min}$, annealing at $50{ }^{\circ} \mathrm{C}$ for $1 \mathrm{~min}$, and chain elongation at $72{ }^{\circ} \mathrm{C}$ for $1.5 \mathrm{~min}$ and finally the ultimate elongation at $72{ }^{\circ} \mathrm{C}$ for $10 \mathrm{~min}$. Also, for simultaneous amplification of chromosome gene I, II, III, IVa and IVb, IVc, IVd, V with $5 \mathrm{~min}$ initial denaturation at $95{ }^{\circ} \mathrm{C}$ and then 10 cycles consisting of denaturation at $95{ }^{\circ} \mathrm{C}$ for $1 \mathrm{~min}$, annealing at $58-60{ }^{\circ} \mathrm{C}$ for $1 \mathrm{~min}$, and chain elongation at $72{ }^{\circ} \mathrm{C}$ for $1 \mathrm{~min}$ finally the ultimate elongation at $72{ }^{\circ} \mathrm{C}$ for $1 \mathrm{~min}$. PCR products were electrophoresed on $1.4 \%$ agarose gel at 90 $\mathrm{V}$ at $75 \mathrm{~min}$, stained with Ethidium Bromide (Sigma USA), and it was imaged the gel document system (BioDoc). The marker DNA (bp 100 and $\mathrm{kb}$ 1) was used to determine the molecular weight.

The produced data gained from using descriptive statistics (frequency- percentage and Mean \pm SD), and Chi-Square Test with SPSS-18 statistical software.

\section{RESULTS}

Of the 230 healthcare workers, 186 (80.9\%) were female and $44(19.1 \%)$ were male. Average age was 40 year. In this study, out of 230 samples, 37 samples $(14.8 \%)$ were colonized with S. aureus. 28 out of $37 \mathrm{~S}$. aureus isolated $(75.7 \%)$ were confirmed as MRSA. The highest rate of isolation MRSA was in the operating room (22.6\%) and surgery $(18.7 \%)$.Data analysis showed that most of the MRSA isolates were found in the age group of 23-30 years. In this group, 13 (34.2\%) had MRSA, and the lowest incidence of MRSA was observed in the age group of 51-60, of which 2 $(26.5 \%)$. In terms of the history of the last antibiotic, among the people with MRSA, the most commonly used penicillin antibiotics were 4 $(33.3 \%)$ and the lowest metronidazole, macrolide and fluoroquinolone were $0 \%$.

Evaluation of antibiotic resistance pattern by disc diffusion method showed that isolates had the highest resistance to penicillin $(100 \%)$, chloramphenicol $(30.4 \%)$, erythromycin $(15.8 \%)$, clindamycin (10.5\%) and the least resistance to (0\%), Co-trimoxazole (1\%), vancomycin (Fig. 1).

Frequency antibiotic resistance of MRSA isolates in different part of hospital is illustrated in Table 2. All of the isolates were sensitive to vancomycin. Whereas all of the isolates were resistant to penicillin and this was found statistically significant $(p \leq 0.05)$.

The MIC results of vancomycin in MRSA isolates showed that $20(71.4 \%)$ sensitive to vancomycin and eight $(28.5 \%)$ had intermediate resistance (MIC $<4-8 \mu \mathrm{g} / \mathrm{ml}$ ). Twenty eight were resistant with cefoxitin disc diffusion test and in these 28 isolates $m e c A$ gene was detected.

Furthermore, screening test in MRSA isolates showed that $2(7.2 \%)$ were sensitive and 26 $(92.8 \%)$ were resistant to methicillin. Frequency of SCCmec types and sub-types were as follow; nine SCCmec I (32.1\%), eight SCCmec IV (28.4\%), five SCCmec II (17.8\%), four SCCmec $V(14.6 \%)$, two SCCmec III (7.1\%). In this study, the results of multiplex PCR showed that of 37 isolates, $28(75.7 \%)$ had methicillin resistance gene (mecA) (Fig.3). also of 28 isolates, 21 (75\%) belong to types I, IV and $V$, which are mainly derived from the community and are responsible for the resistance to penicillin and 
some other beta-lactam. 7 (25\%) of the types II and III, which are often acquired by the hospital and are a factor of multiple resistance to betalactams and other antibiotics.

Also, the frequency of Staphylococcus aureus strains isolated from healthcare workers in different hospitals showed that the highest infection with MRSA was (55.26\%) in Imam Reza Larestan Hospital and the least infection was in Omidvar Evaz Hospital $(5.26 \%)$ were. According the Chi-square and the significance index $(P=0.95)$ and degree of freedom $(P=0)$, there is a significant relationship between the hospital and MRSA infection.

Table 1. Primer, concentration, size and specificity of the generated Amplicons (Reference 16).

Specificity of amplicon

\begin{tabular}{|c|c|c|c|}
\hline sccmec I & $\begin{array}{l}\text { GCTTTAAAGAGTGTCGTTACAGG } \\
\text { GTTCTCTCATAGTATGACGTCC }\end{array}$ & 0.048 & 613 \\
\hline scCmec II & $\begin{array}{l}\text { CGTTGAAGATGATGAAGCG } \\
\text { CGAAATCAATGGTTAATGGACC }\end{array}$ & 0.032 & 398 \\
\hline sccmec III & $\begin{array}{l}\text { CCATATTGTGTACGATGCG } \\
\text { CCTTAGTTGTCGTAACAGATCG }\end{array}$ & 0.04 & 280 \\
\hline scCmec IVa & $\begin{array}{l}\text { GCCTTATTCGAAGAAACCG } \\
\text { CTACTCTTCTGAAAAGCGTCG }\end{array}$ & 0.104 & 776 \\
\hline sccmec IVb & $\begin{array}{l}\text { TCTGGAATTACTTCAGCTGC } \\
\text { AAACAATATTGCTCTCCCTC }\end{array}$ & 0.092 & 493 \\
\hline scCmec IVc & $\begin{array}{l}\text { ACAATATTTGTATTATCGGAGAGC } \\
\text { TTGGTATGAGGTATTGCTGG }\end{array}$ & 0.078 & 200 \\
\hline scCmec IVd & $\begin{array}{l}\text { CTCAAAATACGGACCCCAATACA } \\
\text { TGCTCCAGTAATTGCTAAAG }\end{array}$ & 0.28 & 881 \\
\hline scCmec V & $\begin{array}{l}\text { GAACATTGTTACTTAAATGAGCG } \\
\text { TGAAAGTTGTACCCTTGACACC }\end{array}$ & 0.06 & 325 \\
\hline mecA & $\begin{array}{l}\text { GTG AAG ATA TAC CAA GTG ATT } \\
\text { ATG CGC TAT AGA TTG AAA GGA T }\end{array}$ & 0.046 & 147 \\
\hline
\end{tabular}

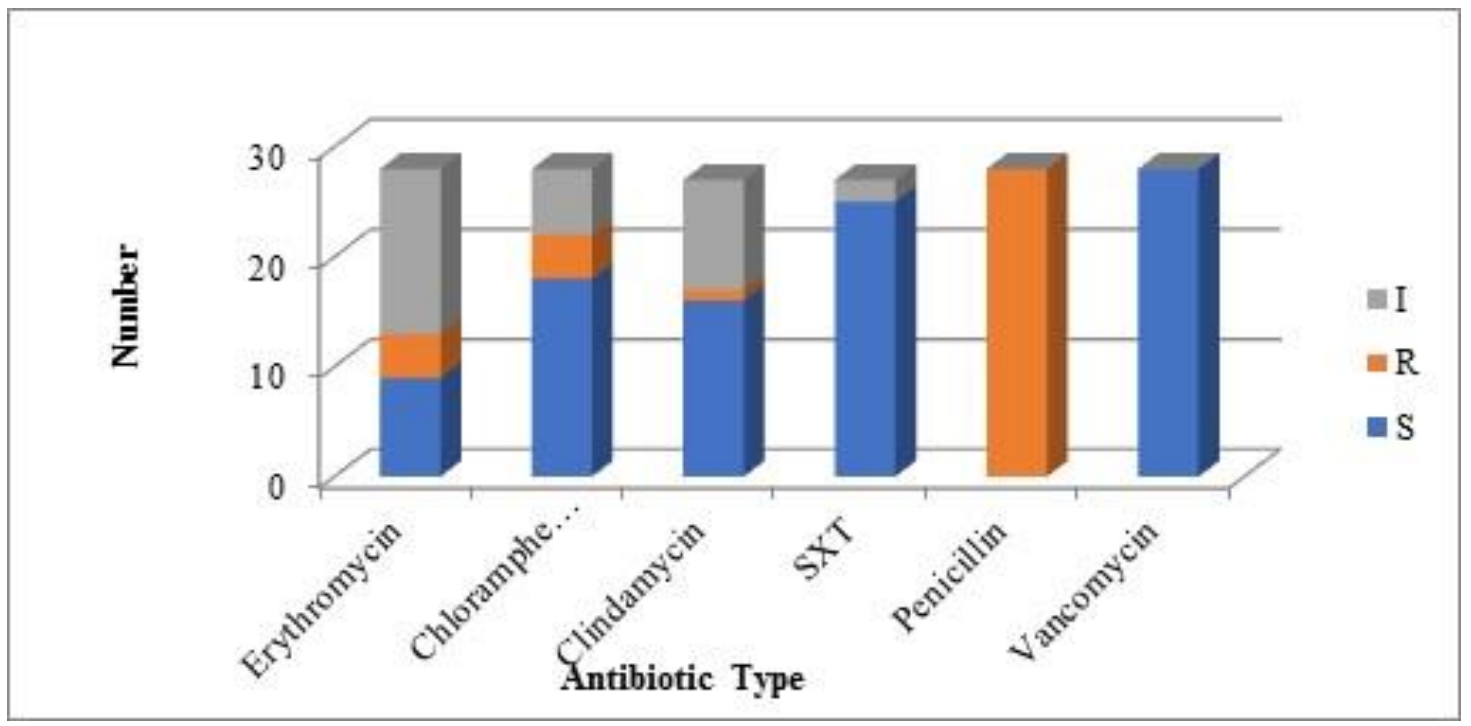

Figure 1. Comparison of frequency distribution of antibiotic resistance in MRSA strains isolated from nasal swabs. 


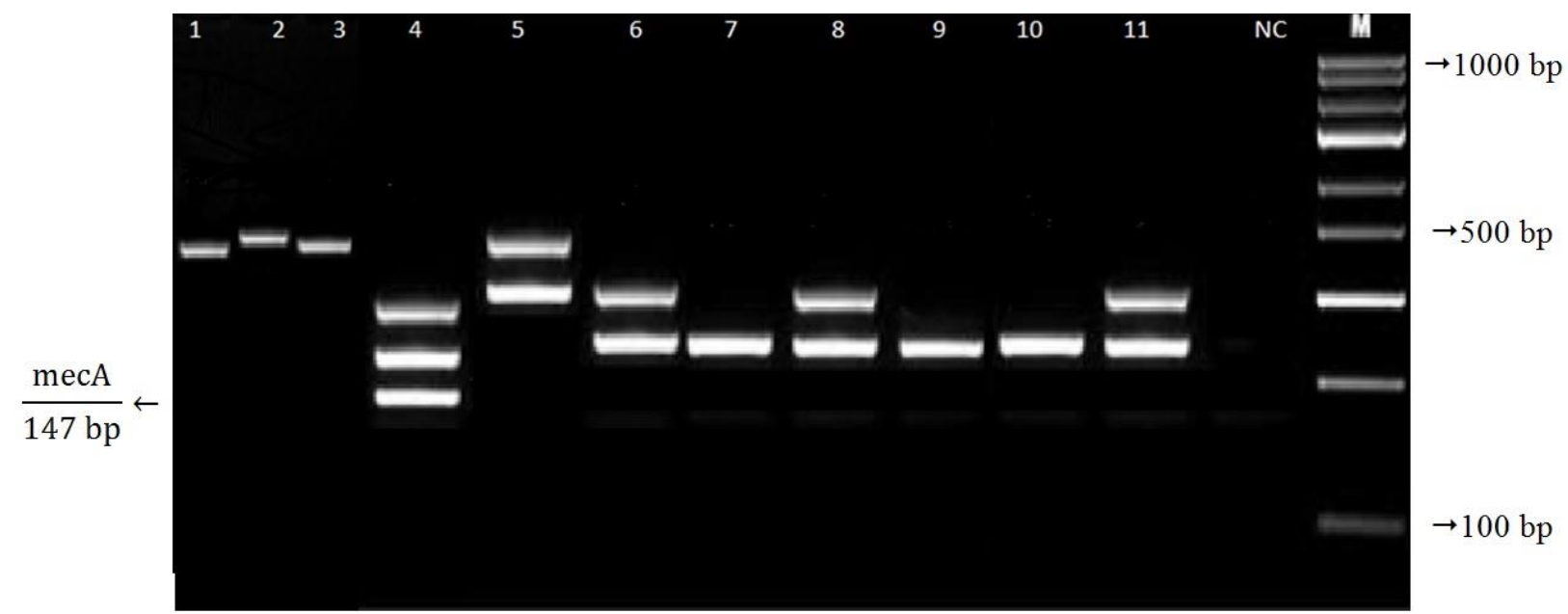

1, 2 and 3 = SCC I Type; 4, 6, 8 and 11= SSC III Type; 5= SSC 5 Type; 7, 9 and 10= SSC IVc Type; NC= Negative Control, M= Marker Figure 2. Amplification pattern of SCCmec typing with Multiplex PCR. in MRSA isolates

\section{DISCUSSION}

Today, the problem of antibiotic resistance could not be solved with the creation stronger antibiotics and bacteria will consistently continue to adapt to their environment by developing resistance to newer antibiotics and serious infections. In Iran also, the prevalence of methicillin-resistant Staphylococcus aureus and resistance against other antibiotics including beta-lactams, aminoglycosides and macrolides has been rising and has reached a significant level [17].

There are several reports of MRSA frequency in Iranian hospitals. Fatholahzadeh et al. isolated 99 MRSA from hospital patients in Tehran during a 15 month period [17]. In the other study, results showed that the rate of MRSA had risen up to $43 \%$ in Nemazi hospital (Shiraz, Iran) during four years [18]. This rate, based on studies conducted in most parts of the country and other parts of the world, indicates a reduction in the prevalence of this resistant strain, which can be attributed to the insight into the correction of antibiotic use among the medical community and the reduction of the threat of methicillin.

In the present study, the prevalence of $S$. aureus was $16.5 \%$ and MRSA in the total number of hospitals in the three Larestan District was $12.2 \%$. but, the bacteria also uses other types of $\mathrm{SCCmec}$ to prevent antibiotics effect, which suggests that they also have multi-drug resistance at the same time as new antibiotics are used and most of the studied strains had multiple resistance (Table 3).

In this study, we found that with disc diffusion method the drug resistance to penicillin (100\%) and oxacillin $(60.5 \%)$ and the least resistance to vancomycin $(0 \%)$ and SXT $(0 \%)$ but the results of MIC by E-test showed that $20(71.4 \%)$ of MRSA were sensitive to vancomycin and 8 $(28.6 \%)$ had intermediate isolates. This suggests that phenotypic methods such as disk diffusion may be subject to errors and mutations. Therefore, using standardized phenotypic methods such as MIC using E-test and molecular methods such as PCR to track the resistance gene and to verify the percentage of vancomycin Resistance $S$. aureus (VRSA) strains is necessary [18].

According to the mentioned cases of false resistance to methicillin and its results, in the present study, agar screening method was used to prevent the detection of false positive results in order to determine definite resistance to methicillin strains. In the current study, 26 isolates out of $28(92.8 \%)$ had mecA gene in agar screening method than oxacillin resistant and all strains lacking $m e c A$ gene were oxacillinsensitive. Havaei et al. in agar screen method found 31 of $35(88.5 \%)$ to harbor mecA gene are resistant to methicillin [19].

In two separate studies by wallet et al. [20], and Sakoulas et al., the results of agar screen and PCR were compared and reported an equivalent sensitivity (99\%) and (96\%) respectively. 
Results of cefoxitin disc diffusion test is in comfortable with the PCR for mecA gene, thus this test can be an alternative to $\mathrm{PCR}$ for detection MRSA. Although PCR is a sensitive and accurate method for detecting resistance and is an ideal method for detecting MRSA strains [21]

We also found that in PCR method, more than $70 \%$ of Staphylococcus aureus isolates have $m e c A$ gene of the 28 isolates of MRSA, 21 (75\%) were CA-MRSA and 7 (25\%) HA-MRSA. Therefore, the most isolated strains of MRSA were the source of this community. Sccmec Type I and Sccmec Type I/ have been noticed in our sample.

In a study carried by Ameer Abbas et al. [22], in the Indian hospital, it was found that of 201 isolates of $S$. aureus, 142 (28.6\%) HA-MRSA and $58(11.6 \%)$ CA-MRSA.

Over the past decade, CA-MRSA has emerged globally. CA-MRSA than HA-MRSA due to the formation of Penton Valentin Leukocidin toxin has the higher potential for severe illnesses [22]. Therefore, an alert in the Larestan Region is considered. Since type $I$ is the source of the community and type $\mathrm{II}$ is the origin of that hospital, the need to control criteria of the hospital infection is to prevent crosscontamination.

To conclude, we suggest that treatment of MRSA-mediated carriers should be taken to prevent spread of MRSA strains in the hospital and community environments. Further research is needed to understand the $\mathrm{SCCmec}$ elements of MRSA isolates.

\section{ACKNOWLEDGMENTS}

Conflict of interest: The authors declare no personal or financial conflict of interest.

Acknowledgment: This study is financially supported by Faculty of Medical Sciences, Larestan, Iran.

\section{REFERENCES}

1.Changchien $\mathrm{CH}$, Chen SW, Chen YY, Chu C. Antibiotic susceptibility and genomic variations in Staphylococcus aureus associated with Skin and Soft Tissue Infection (SSTI) disease groups. BMC Infect Dis 2016; 10: 276-280.

2.Davoodabadi F, Mobasherizadeh S, Mostafavizadeh $\mathrm{K}$, et al. Nasal colonization in children with community acquired methicillin-resistant Staphylococcus aureus. Adv Biomed Res 2016; 11: 86-90.

3.Ilyasu G, Daiyab FM, Tiamiyu AB, et al. Nosocomial infections and resistance pattern of common bacterial isolates in an intensive care unit of a tertiary hospital in Nigeria: A 4-year review. J Crit Care 2016; 34: 116120.

4.Gunawardena ND, Thevanesam V, Kanakaratne N, et al. Molecular identification of methicillin resistance and virulence marker in Staphylococcus aureus $\mathrm{J}$ infect Dis 2012; 2: 18-29.

5.Hou BP, Zhou S, Hua DH, et al. Staphylococcal cassette chromosome mec (SCCmec) analysis and antimicrobial susceptibility profiles of methicillin resistant Staphylococcus aureus (MRSA) isolates in a teaching hospital, Shantou, China. Afr J Microbiol Res 2010; 4: 844-848.

6.Grundmann $\mathrm{H}$, Aires-de-Sousa M, Boyce J, et al. Emergence and resurgence of methicillin resistant Staphylococcus aureus as a public-health threat. Lancet. 2006; 368: 874-885.

7.Baba-Moussa L, Sina $H$, Scheftel JM, et al. Staphylococcal Panton-Valentine Leukocidin as a major virulence factor associated to furuncles. Clin infect Dis 2011; 6: 257-260.

8.Japoni A, Jamalidoust M, Farshad, S, et al. Characterization of $\mathrm{SCCmec}$, types and antibacterial susceptibility patterns of methicillin resistant Staphylococcus aureus in Southern Iran. J Infect Dis 2011; 64: 28-33.

9.Tsubakishita S, Kuwahara-Arai K, Sasaki et al. Origin and molecular evolution of the determinant of methicillin resistance in Staphylococci. Antimicrob Agents and Chemother 2010; 54: 352-359.

10.Azimian A, Najar-Pirayesh S, Mirab-Samiees S. Occurrence of methicillin resistant Staphylococcus aureus (MRSA) among clinical samples in TehranIran and its correlation with polymorphism of specific accessory gene regulator (agr) groups. Braz J Microbiol 2012; 43: 779-785.

11.Teruyo I, Katayamay, H, Hiramatsu K. Classification of staphylococcal cassette chromosome mec (SCCmec): Guidelines for reporting novel SCCmec mec elements. Antimicrob Agents Chemother 2009; 53: 4961-4967.

12.Brown DFJ, Edwards DI, Hawkey PM, et al. Guidelines for the laboratory diagnosis and susceptibility testing of Methicillin-Resistant Staphylococcus aureus (MRSA). Antimicrob Agents Chemther 2005; 56: 1000-1018.

13.Performance Standards for Antimicrobial Susceptibility Testing; 21st informational supplement. Clinical and laboratory standards institute (CLSI), 2012. 
14.Klein E, Smith DL, Laxminarayan R. Hospitalizations and deaths caused by methicillin resistant Staphylococcus aureus, United States, 1999-2005 Emerg Infect Dis 2007; 12: 1840-1846.

15.Klevens RM, Morrison MA, Nadle J, et al. Invasive methicillin resistant Staphylococcus aureus infections in the United States. JAMA 2007; 15: 1763-1765.

16.Zhang K, Mcclure JA, Elsayed S, et al. Novel multiplex PCR for characterization and concomitant subtyping of Staphylococcal cassette chromosome mec typing I to $\mathrm{V}$ in Methicillin Resistant Staphylococcus aureuse. J Antimicrob Agents Chemother 2005; 43: 5026-5033.

17.Fatholahzadeh B, Emaneini M, Gilbert G, et al. Staphylococcal Cassette Chromosome mec (SCCmec) Analysis and Antimicrobial Susceptibility Patterns of Methicillin-Resistant Staphylococcus aureus (MRSA) Isolates in Tehran, Iran. Microb Drug Resist 2008; 14: 217-220.

18.Japoni A, Alborzi A, Orafa F, et al. Distribution Patterns of Methicillin Resistance genes (mecA) in Staphylococcus aureus isolated from clinical specimens. Iranian Biomedical Journal 2004; 8: 173178.

19. Havaei SA, Karbalaeizadeh Babaki M, Pishva E. Comparison of the results of polymerase chain reaction and oxacillin agar dilution methods in determining resistance to methicillin in isolated staphyloccus aureus at Alzahra Hospital, Isfahan, Iran. J Isfahan Med Sch 2011; 29: 1175-82. [In Persian].

20.Perez LR, Dias C, Azevedo PA. Agar dilution and agar screen with oxacillin: what is known and what is unknown in detection of MRSA. J Microbiol 2008; 57: 954-956.

21.Venkatakrishna RL, Kishore BG, Manohar KS, et al. Detection of methicillin resistance in Staphylococcus aureus: Comparison of Disc diffusion and MIC with mecA gene detection by PCR. J Pharm Biol Sci 2011, 1: 518-521.

22. Hota B, Lyles R, Rim J, et al. Predictors of clinical virulence in community-onset methicillin-resistant Staphylococcus aureus infections. Clin Inf Dis 2011; 53: 757-765. 